\title{
Electric and Dielectric behavior of Ni-Co-Cd Ferrite
}

\author{
B. A. Aldar, R. K. Pinjari, N. M. Burange* \\ Department of Physics, Smt. Kasturbai Walchand College, Sangli, Maharashtra, India.
}

\begin{abstract}
Cadmium doped nickel-cobalt ferrite with chemical formula $\mathrm{Ni}_{0.8-x} \mathrm{Co}_{0.2} \mathrm{Cd}_{x} \mathrm{Fe}_{2} \mathrm{O}_{4}(x=0.1,0.2$ and $0.3)$ is prepared by standard double sintering ceramic method. Electric and dielectric properties of nickel cobalt cadmium ferrite are investigated. Formation of single phase is confirmed by X-ray Diffraction pattern. The average grain size of the samples is determined by scanning electron micrographs. The D.C resistivity $(\rho)$ is determined as a function of temperature in the range $300 \mathrm{~K}-1073 \mathrm{~K}$ by two probe method. Dielectric constant $(\dot{\varepsilon})$ is determined by measuring capacitance $\left(C_{p}\right)$. Variations of Dielectric constant (') with frequency as well as temperature are studied. A.C. conductivity $\left(\sigma_{a c}\right)$ is derived from dielectric constant $(\dot{\varepsilon})$ and loss tangent (tan $\left.\delta\right)$ values
\end{abstract}

Keywords: Dielectric properties. Electric properties, NiCoCd Ferrite, SEM, XRD.

\section{Introduction}

Ferrites are used in various technological applications due to their high electrical resistivity and wide ranges of saturation magnetization .Ferrites are magnetic materials with cubic spinel structure having formula $\mathrm{AB}_{2} \mathrm{O}_{4}$. In ferrite ' $\mathrm{A}$ ' is divalent metal ion and ' $\mathrm{B}$ ' is trivalent metal ion. Mostly divalent metal ions occupies octahedral site and trivalent metal ion occupies tetrahedral site with exception of cadmium ion $\left(\mathrm{Cd}^{2+}\right)$ and zinc ion $\left(\mathrm{Zn}^{2+}\right)$. In nickel cobalt ferrite divalent metal ions $\left(\mathrm{Ni}^{2+}\right.$ and $\left.\mathrm{Co}^{2+}\right)$ occupies octahedral site and trivalent metal ions $\left(\mathrm{Fe}^{3+}\right)$ occupies octahedral which forms inverse spinel structure. Ferrite materials possess high permeability, high magnetization and low losses at higher frequencies due to this ferrites have large technological applications such as LPG gas sensor, humidity sensor [1, 2, 3, 4].

Investigation of electrical and magnetic properties on cobalt, cadmium and zinc doped nickel ferrite have also been studied in order to improve resistivity, permeability and magnetization [5-8].Hence to study mechanism of electrical conduction and dielectric properties we have prepared $\mathrm{Ni}_{0.8-\mathrm{x}} \mathrm{Co}_{0.2} \mathrm{Cd}_{\mathrm{x}} \mathrm{Fe}_{2} \mathrm{O}_{4}$ where $\mathrm{x}=0.1,0.2$, and 0.3 .

\section{Experimental Details}

The nickel cobalt cadmium ferrite having composition $\mathrm{Ni}_{0.8-\mathrm{x}} \mathrm{Co}_{0.2} \mathrm{Cd}_{\mathrm{x}} \mathrm{Fe}_{2} \mathrm{O}_{4}(\mathrm{x}=0.1,0.2,0.3)$ is prepared using standard double sintering ceramic method. The stoichiometric amounts of AR grade powders of carbonates of nickel, cobalt and cadmium and iron oxide were weighed and thoroughly mixed in agate mortar to form homogenous mixture. This homogenous mixture was presintered at $950^{\circ} \mathrm{C}$ for 12 hours in muffle furnace. These compositions were then mixed with polyvinyl alcohol as a binder and using hydraulic press pellets having thickness of $2-3 \mathrm{~mm}$ and diameter $10-15 \mathrm{~mm}$ were prepared. These pellets and remaining powder were final sintered at $1100^{\circ} \mathrm{C}$ for 12 hours. These samples in the form of pellets were used to study electrical and dielectric properties.

\section{Experimental Analysis}

2.1 XRD Analysis

The formation of ferrite phase without any impurity was confirmed by using X-ray diffractometer (Bruker D8 Advance) using $\mathrm{Cu}-\mathrm{K} \alpha$ radiation $\left(\lambda=1.5418 \AA\right.$ ). Fig.1a) represents $\mathrm{X}$-ray diffraction pattern of $\mathrm{Ni}_{0.8-}$ ${ }_{x} \mathrm{Co}_{0.2} \mathrm{Cd}_{\mathrm{x}} \mathrm{Fe}_{2} \mathrm{O}_{4}$ where $\mathrm{x}=0.1,0.2,0.3$. The sample show all the characteristics peaks of ferrite material having intense peak at (311) plane. The lattice parameter calculated from further analysis which is shown in Table 1. It is observed that the lattice parameter increases with the increase in $\mathrm{Cd}^{2+}$ concentration. Similar linear dependence results have also been observed to many researchers. $[9,10]$. Increase in lattice parameter with $\mathrm{Cd}^{2+}$ leads due to the difference in ionic sizes of the component ions. $\mathrm{Cd}^{2+}$ ions have larger ionic radius $(0.97 \AA)$ then $\mathrm{Ni}^{2+}(0.74 \AA), \mathrm{Co}^{2+}(0.78 \AA), \mathrm{Fe}^{3+}(0.67 \AA)$ ions. By using Scherrer formula crystallite size was calculated from XRD line width of (311) peak. Fig.1b) shows the variation of crystallite size and lattice parameter with cadmium content. 


\subsection{SEM Analysis}

SEM micrographs were taken by using SEM model -JEOL JSM 6360. Fig.2. represents SEM micrographs of $\mathrm{Ni}_{0.8-\mathrm{x}} \mathrm{Co}_{0.2} \mathrm{Cd}_{\mathrm{x}} \mathrm{Fe}_{2} \mathrm{O}_{4}$ where $\mathrm{x}=0.1,0.2,0.3$. From SEM micrographs average grain size was calculated by using Cottrell's formula. The average grain size was found to be within the range $1.46 \mu \mathrm{m}$ to 1.89 $\mu \mathrm{m}$. It is observed that average grain size increases with increase in cadmium concentration and recorded in table1.

\subsection{D.C. Resistivity}

DC resistivity determined by using to two probe method within the range of 300K-1073K. Fig.3 shows the variation of D.C. resistivity with temperature. It is observed that all the samples show the decrease in resistivity with the increase in temperature, which corresponds to the semiconducting behavior of the materials. The decrease in resistivity with increase of temperature may be due to the thermally activated drift mobility of charge carriers [11]. Conduction in ferrite is found to be due to hopping of electrons from $\mathrm{Fe}^{3+}$ to $\mathrm{Fe}^{2+}$ ions. The change of slop of the plot indicates the change in conduction mechanism. Temperature dependent mobility of charge carriers is characterized by activation energy. It is found that with increase in cadmium content activation energy decreases. Similar results are obtained by O. M. Hemeda and M.M. Barakat in case of CoCd Ferrite [12].The decrease in resistivity may be due to distortion of lattice [13]. The distortion of lattice may be due to replacement of $\mathrm{Ni}^{2+}(0.74 \AA)$ having smaller ionic radius by $\mathrm{Cd}^{2+}(0.97 \AA)$ of bigger ionic radius.

\subsection{Dielectric Properties}

Dielectric properties were studied by measuring capacitance $(\mathrm{Cp})$ and loss tangent ( $\tan \delta$ ) by using Hioki 3532-50 LCR Hi tester at frequencies $1 \mathrm{kHz}, 10 \mathrm{kHz}, 100 \mathrm{kHz}$ and $1 \mathrm{MHz}$. Fig.4a) and Fig.4b) represent the variation of dielectric constant $(\dot{\varepsilon})$ and loss tangent $(\tan \delta)$ with frequency. It is observed that both dielectric constant as well as loss tangent decreases with increase in frequency. The decrease in dielectric constant with frequency indicates dielectric dispersion is at low frequency region which is due to Maxwell-Wagner type of interfacial polarization [14] in agreement with Koop's phenomenological theory [15]. The dielectric constant decreases rapidly at low frequencies and becomes quite slow at high frequencies. The higher value of dielectric constant at lower frequencies is explained on the basis of space charge polarization.

Fig.5 represents the variation of dielectric constant with temperature. Temperature dependent dielectric study shows that dielectric constant increases slowly with increase in temperature and thereafter increases rapidly up to the Curie temperature and then decreases indicating phase transition from ferromagnetic to paramagnetic state. Increase in dielectric constant with temperature is mainly due to interfacial and dipolar polarizations, which are strongly temperature dependent. The increase in polarization results accumulation of charges at grain boundary. Beyond a certain temperature the charges acquire sufficient thermal energy to overcome the resistive barrier at the grain boundary and conduction takes place resulting in decrease in polarization [16]. It is also observed that Curie temperature decreases with increase in cadmium content [Table.1]. The decrease in Curie temperature with increasing cadmium content is may be due to the decrease of $\mathrm{Fe}^{3+}$ ion, which reduces the $\mathrm{AB}$ exchange interaction of the type $\mathrm{Fe}_{\mathrm{A}}^{3+}-\mathrm{O}-\mathrm{Fe}_{\mathrm{B}}^{3+}[17]$. As a result of which the thermal energy required to offset the alignment of the magnetic moment decreases, leading to a decrease in Curie temperature.

Fig.5d) represents the variation of $\mathrm{AC}$ conductivity with frequency for $\mathrm{x}=0.1,0.2$ and 0.3 . It is observed that $\mathrm{AC}$ conductivity increases with increase in frequency which is normal behavior of ferrite. Increase in $\mathrm{AC}$ conductivity with frequency is due to hopping of charge carriers between $\mathrm{Fe}^{2+}-\mathrm{Fe}^{3+}$ on octahedral site [17].

\section{Figures and Tables}

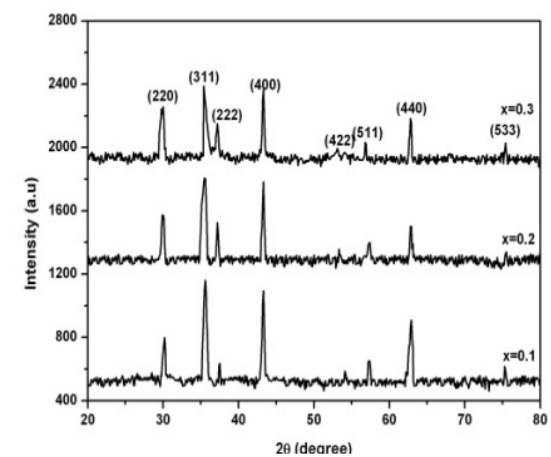

Fig.1a) XRD pattern of $\mathrm{Ni}_{0.8-\mathrm{x}} \mathrm{Co}_{0.2} \mathrm{Cd}_{\mathrm{x}} \mathrm{Fe}_{2} \mathrm{O}_{4}$ Ferrite

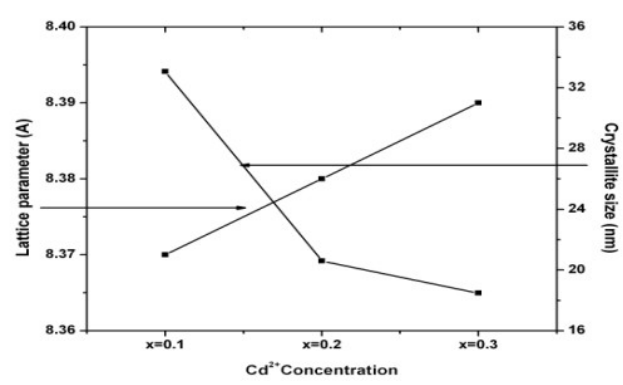

Fig.1b). Variation of Lattice parameter and crystallite size with $\mathrm{Cd}^{2+}$ concentration for $\mathrm{Ni}_{0.8-\mathrm{x}} \mathrm{Co}_{0.2} \mathrm{Cd}_{\mathrm{x}} \mathrm{Fe}_{2} \mathrm{O}_{4}$ Ferrite 


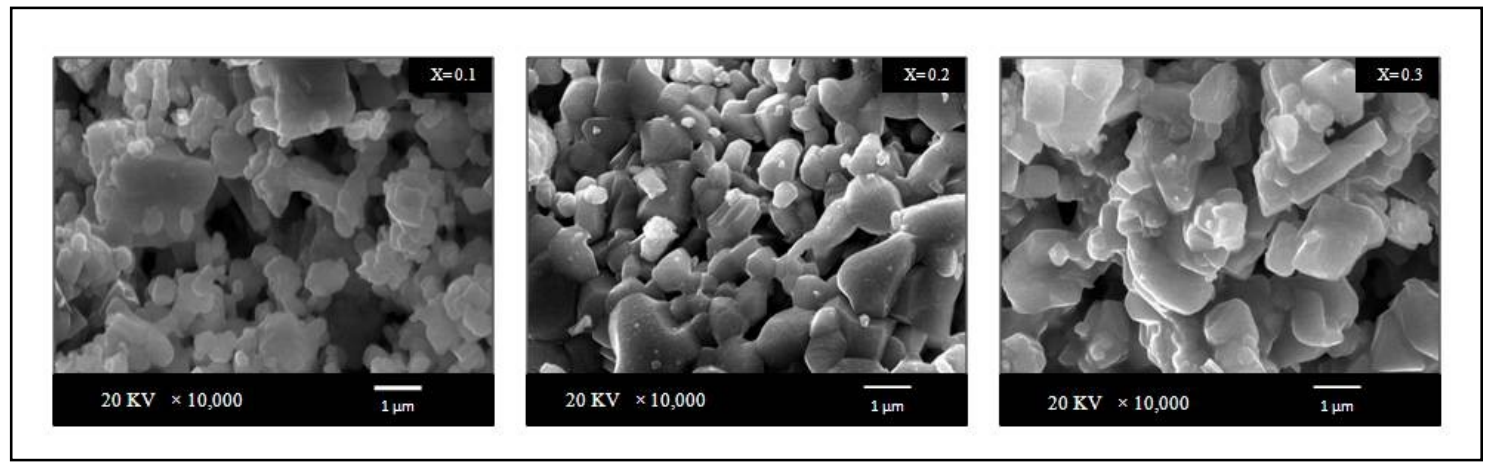

Fig.2. SEM micrographs of $\mathrm{Ni}_{0.8-\mathrm{x}} \mathrm{Co}_{0.2} \mathrm{Cd}_{\mathrm{x}} \mathrm{Fe}_{2} \mathrm{O}_{4}$ Ferrite

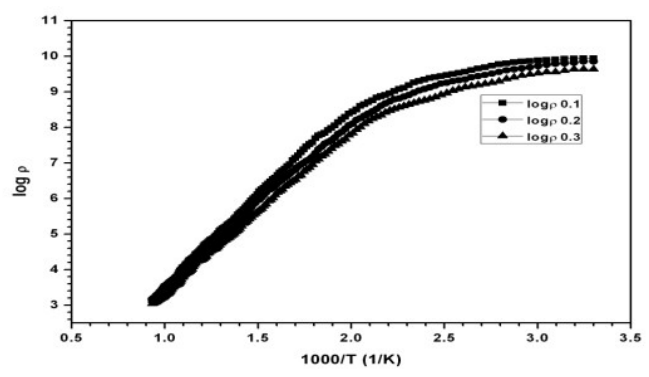

Fig.3. Variation of resistivity with temperature of $\mathrm{Ni}_{0.8-\mathrm{x}} \mathrm{Co}_{0.2} \mathrm{Cd}_{\mathrm{x}} \mathrm{Fe}_{2} \mathrm{O}_{4}$ Ferrite

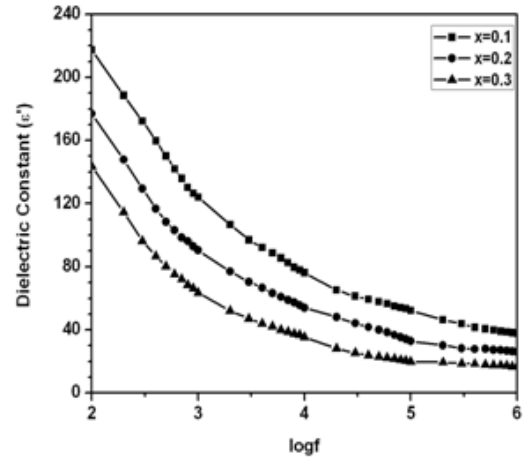

Fig.4a) Variation of Dielectric Constant ( $\dot{\varepsilon})$ with frequency for $\mathrm{Ni}_{0.8-\mathrm{x}} \mathrm{Co}_{0.2} \mathrm{Cd}_{\mathbf{x}} \mathrm{Fe}_{2} \mathrm{O}_{4}$ Ferrite

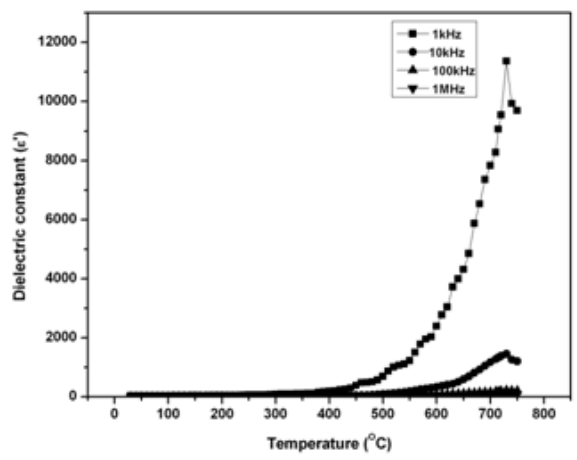

Fig.5a).Variation of dielectric constant with temperature for $\mathrm{Ni}_{0.7} \mathrm{Co}_{0.2} \mathrm{Cd}_{0.1} \mathrm{Fe}_{2} \mathrm{O}_{4}$ Ferrite

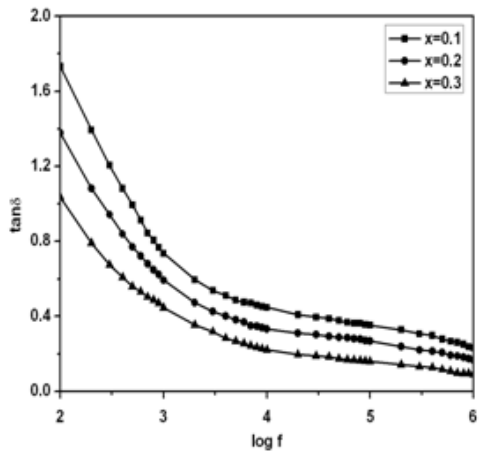

Fig.4b). Variation of Dielectric Loss (tan $\delta)$ with frequency for $\mathrm{Ni}_{0.8-\mathrm{x}} \mathrm{Co}_{0.2} \mathrm{Cd}_{\mathrm{x}} \mathrm{Fe}_{2} \mathrm{O}_{4}$ Ferrite

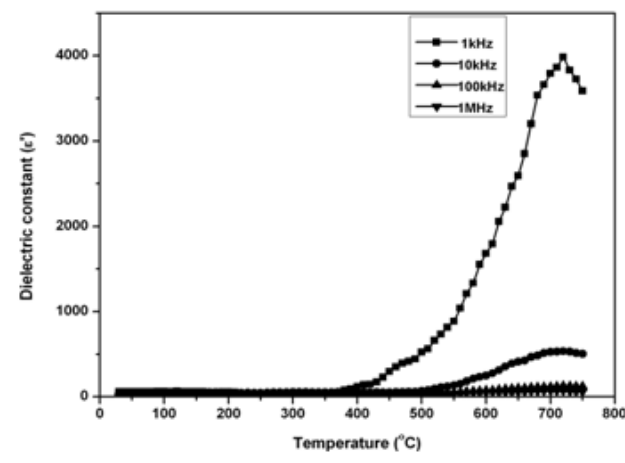

Fig.5b).Variation of dielectric constant with temperature for $\mathrm{Ni}_{0.6} \mathrm{Co}_{0.2} \mathrm{Cd}_{0.2} \mathrm{Fe}_{2} \mathrm{O}_{4}$ Ferrite 


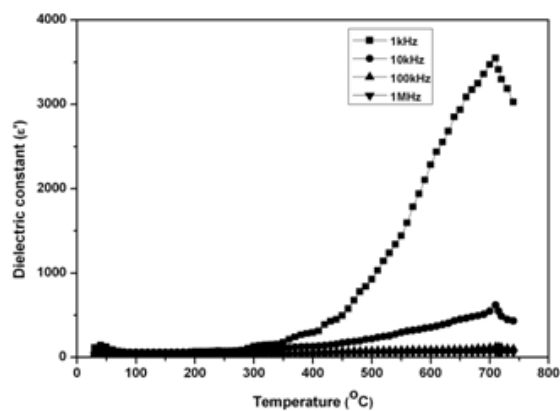

Fig.5c).Variation of dielectric constant with temperature for $\mathrm{Ni}_{0.5} \mathrm{Co}_{0.2} \mathrm{Cd}_{0.3} \mathrm{Fe}_{2} \mathrm{O}_{4}$ Ferrite

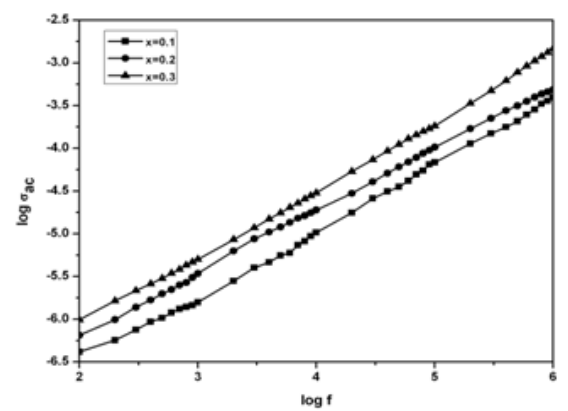

Fig.5d).Variation of AC conductivity with frequency for $\mathrm{Ni}_{0.8-x} \mathrm{Co}_{0.2} \mathrm{Cd}_{\mathbf{x}} \mathrm{Fe}_{2} \mathrm{O}_{4}$, Ferrite

\begin{tabular}{|c|c|c|c|c|c|c|c|}
\hline Composition & $\begin{array}{c}\text { Lattice } \\
\text { Parameter } \\
\mathbf{a}(\AA)\end{array}$ & $\begin{array}{c}\text { Crystallite } \\
\text { size } \\
(\mathbf{n m})\end{array}$ & $\begin{array}{c}\text { Average } \\
\text { Grain } \\
\text { Size }(\mu \mathrm{m})\end{array}$ & $\begin{array}{c}\text { Activation } \\
\text { Energy in } \\
\text { paramagnetic } \\
\text { region } \\
(\Delta \mathrm{E}) \mathrm{eV}\end{array}$ & $\begin{array}{c}\text { Resistivity } \\
\text { at } \rho_{\mathrm{T}} \\
(\Omega \mathbf{c m})\end{array}$ & $\begin{array}{c}\text { Curie } \\
\text { Temperat } \\
\text { ure } \\
\mathbf{T}_{\mathrm{c}}\left({ }^{0} \mathrm{C}\right)\end{array}$ & $\begin{array}{c}\text { Dielectric } \\
\text { const. }(\dot{\varepsilon}) \\
\text { at } T_{\mathrm{c}} \\
(1 \mathrm{kHz})\end{array}$ \\
\hline $\mathrm{x}=0.1$ & 8.37 & 33.07 & 1.46 & 0.801 & $8.74 \times 10^{9}$ & 730 & 11368 \\
\hline $\mathrm{x}=0.2$ & 8.38 & 20.06 & 1.69 & 0.671 & $7.12 \times 10^{9}$ & 720 & 3985 \\
\hline $\mathrm{x}=0.3$ & 8.39 & 18.49 & 1.89 & 0.570 & $4.31 \times 10^{9}$ & 710 & 3547 \\
\hline
\end{tabular}

\section{Conclusions}

$\mathrm{Ni}_{0.8-\mathrm{x}} \mathrm{Co}_{0.2} \mathrm{Cd}_{\mathrm{x}} \mathrm{Fe}_{2} \mathrm{O}_{4}$ Ferrites ( $\mathrm{x}=0.1,0.2,0.3$ ) were prepared standard double sintering ceramic method. $\mathrm{X}$-ray diffraction study confirms the formation of single phase without any impurity. All sample show decrease in resistivity with increase in temperature. The increase in cadmium content causes decrease in the resistivity of the samples. The decrease in dielectric constant with increasing frequency shows dielectric dispersion is in the low frequency region. Temperature dependent dielectric study shows the dielectric constant initially increases slowly and thereafter increases rapidly up to the Curie temperature and then decreases. The decrease in dielectric constant after Curie temperature indicates transition from ferromagnetic state to paramagnetic state. $\mathrm{AC}$ conductivity increases with increase in frequency which is due to small polaron hopping of charge carriers between $\mathrm{Fe}^{2+}-\mathrm{Fe}^{3+}$.

\section{Acknowledgement}

We are thankful to U.G.C New Delhi for providing financial support for doing this research work under scheme of Major Research Project to college Teachers.

\section{References}

[1] Andris Sutka, Rainer Parnab, Gundars Mezinskisa, Vambola Kisandb, Sensors and Actuators B 192 (2014) 173- 180.

[2] Anuj Jain, Ravi Kant Baranwal, Ajaya Bharti, Z. Vakil, and C. S. Prajapati, The Scientific World Journal, Volume 2013, Article ID 790359, 7 pages.

[3] Ovidiu Caltun, Ioan Dumitru, Marcel Feder, Nicoleta Lupu, Horia Chiria, Journal of Magnetism and Magnetic Materials 320 (2008) e869-e873.

[4] R.K. Kotnala, Jyoti Shah, Bhikham Singh, Hari kishan, Sukhvir Singh, S.K. Dhawan, A. Sengupta, Sensors and Actuators B 129 (2008) 909-914.

[5] R.C. Kambale, P.A. Shaikh, S.S. Kamble, Y.D. Kolekar, Journal of Alloys and Compounds 478 (2009) $599-603$.

[6] V.L. Mathe, R.B. Kamble, Materials Research Bulletin 43 (2008) 2160-2165.

[7] D. Ravinder ,T. Alivelu Manga, Materials Letters 41 (1999) 254-260.

[8] N. Rezlescu and E. Rezlescu, Physica Status Solidi (A), Vol. 23, (1974) No. 2.

[9] M.B.Shelar, P.A.Jadhav, D.R.Patil, B.K.Chougule, Vijaya Puri ,Journal of Magnetism and Magnetic Materials 322 (2010) $3355-$ 3358 .

[10] A. M. Abdeena, O.M. Hemedaa,, E.E. Assemb, M.M. El-Sehlya, Journal of Magnetism and Magnetic Materials 238 (2002) 75-83.

[11] R.S. Devan, Y.D. Kolekar, B.K. Chougule, J. Phys.: Condens. Matter 18 (2006)9809.

[12] O. M. Hemeda, M. M. Barakat, Journal of Magnetism and Magnetic Materials 223 , (2001)127-132.

[13] L.Wu, T.S.Wu, C.C. Andwei, J. Phys. D: Appl. Phys. 13 (1980) 259.

[14] K.W. Wagner, Ann. Physik., 40(1993) 818.

[15] C.G. Koops, Phys. Rev. 83 (1951) 121.

[16] L.L. Hench, J.K. West, "Principles of Electronic Ceramics" John Wiley and Sons, New York 73. (1990) 205.

[17] A.M. Abo El Ata, S.M. Attia, D. El Kony, A.H. Al-Hammadi, Journal of Magnetism and Magnetic Materials 295 (2005) $28-36$.

[18] Gangatharan Sathishkumar, Chidambaram Venkataraju, Kandasamy Sivakumar, Materials Sciences and Applications, 2010, 1, 1924. 